\title{
Title: Veterans' perceptions of racial bias in VA mental healthcare and their impacts on patient engagement and patient-provider communication
}

Authors: Johanne Eliacin, Marianne S. Matthias, Brooke Cunningham, and Diana Burgess

Johanne Eliacin, PhD, HPSPP (Corresponding Author)

VA HSR\&D Center for Health Information and Communication, Richard L. Roudebush VAMC; ACT Center of Indiana, Psychology Department, IUPUI; Regenstrief Institute, Inc., Indianapolis, IN johanne.eliacin@va.gov

Marianne S. Matthias, $\mathrm{PhD}$

VA HSR\&D Center for Health Information and Communication, Richard L. Roudebush VAMC, Department of Communication Studies, IUPUI, Regenstrief Institute, Inc., Indianapolis, IN mmatthia@iupui.edu

Brooke Cunningham, MD

Department of Family Medicine and Community Health 420 Delaware St SE, MMC 381, Minneapolis MN, USA; bcunning@umn.edu.

Diana Burgess, PhD.

Center for Chronic Disease Outcomes Research (a VA HSR\&D Center of Excellence), Veterans

Affairs Medical Center, Minneapolis, MN, USA diana.burgess@,va.gov.

Funding: This work was supported by Veterans Affairs Health Service Research \& Development PPO \# 13-39 (PI: Eliacin) and Veterans Affairs Health Service Research \& Development Research Career Scientist Award [\#RCS 10-185] to Dr. Burgess. Dr. Eliacin and Matthias were also supported in part by VA HSR\&D Center for Health Information and Communication, CIN 13-416. In addition, Dr. Eliacin received support from a VA HSR\&D Career Development Award CDA 16-153 (PI: Eliacin).

Views expressed in this article are those of the authors and do not necessarily reflect the position or policy of the Department of Veterans Affairs or the United States government.

Acknowledgments: We would like to thank the study participants for making this work possible.

Conflict of interest: The authors declare that they have no competing interests.

This is the author's manuscript of the article published in final edited form as:

Eliacin, J., Matthias, M. S., Cunningham, B., \& Burgess, D. J. (2020). Veterans' perceptions of racial bias in VA mental healthcare and their impacts on patient engagement and patient-provider communication. Patient Education and Counseling, 103(9), 1798-1804. https://doi.org/10.1016/j.pec.2020.03.017 


\begin{abstract}
Objectives: Drawing from social identity threat theory, which posits that stigmatized groups are attuned to situational cues that signal racial bias, we examined how African-American veterans evaluate verbal and non-verbal cues in their mental health encounters. We also explored how their evaluations of perceived racial bias might influence their healthcare engagement behaviors and communication.
\end{abstract}

Methods: We interviewed 85 African-American veterans who were receiving mental health services from the US Department of Veterans Affairs (VA), examining their views and experiences of race in healthcare. We analyzed the data using a constructivist grounded theory approach.

Results: Participants identified several identity threatening cues that include lack of racial diversity representation in healthcare settings, and perceptions of providers' fears of Black patients. We describe how participants evaluated situational cues as identity threats, and how these cues affected their engagement behaviors and healthcare communication.

Conclusion: Our findings revealed situational cues within clinical encounters that create for Black veterans, fear of being negatively judged based on stereotypes that have characterized African-Americans.

Practice Implications:

We discuss the implications of these findings and provide suggestions on how to create identity safe environments for minority patients that include delivery of person-centered care, and organizational structures that reduce providers' burnout. 


\section{Introduction}

Racial bias in healthcare is a major contributor to healthcare disparities [1-5]. Although most healthcare providers are committed to providing equitable treatment to all patients regardless of their racial backgrounds, they are not immune to social and cultural influences that can lead to implicit racial bias. Providers' implicit racial biases can negatively impact patients' health outcomes and healthcare experiences [1, 3, 6-8]. For example, they may lead to lower quality healthcare for Blacks relative to Whites, especially in situations where providers experience high cognitive demand and time pressure $[5,9,10]$.

In turn, patients' perceptions of racial bias in healthcare are associated with suboptimal care $[11,12]$, delays in obtaining medical care [13-15], under-utilization of preventive and mental health care $[16,17]$, less adherence to recommended treatment $[18,19]$, and poorer treatment outcomes $[20,21]$. Perceptions of racial bias also negatively impact the patientprovider relationship [22-24], which is important because this relationship is at the center of person-centered care [25-27]. The patient-provider relationship also influences patients' engagement in care [28], and is associated with positive healthcare outcomes [29, 30].

This study builds on prior research examining patients' perceptions of bias in medicine [31-37]. While these works have provided valuable insights into minority patients' perceived views of provider bias and their effects, they are primarily quantitative, and focus on the technical aspects of care such as disparities in diagnoses and treatment. Less is known about the interpersonal aspects of bias, such as what contextual factors patients perceive as racial bias and how such factors may contribute to patient healthcare engagement and patient-provider communication. 
Studies that have explored minority patients' views of bias have identified factors such as feelings of disrespect and experiences of cultural incompetence as contributors to perceptions of racial bias [38-42]. The present study adds to this growing literature by drawing from social identity theory to explore Black veterans' views of verbal and non-verbal cues that signal to them threats of racial bias in mental health encounters. Social identity theory posits that stigmatized groups are attuned to cues that signal whether they may be devalued in a setting because of their social identity [43-46]. Using this framework, we sought to examine situational cues that indicate social identity contingencies in health encounters for Black veterans judgments, stereotypes, or negative interactional experiences that are tied to their racial identity. Moreover, because of the important role of patients' perceptions of racial bias in the patientprovider relationship $[22,35,47,48]$ and healthcare disparities $[14,37,49,50]$, we also explored how their evaluations might influence their engagement behaviors and healthcare communication.

Research studies have shown that Blacks' perceptions of what behaviors count as racism differ from Whites' perceptions primarily because of their racial group membership [51]. Due to their history of experiencing racial discrimination, Blacks have group-based motivations to attend to different information and adopt lower threshold for cues that suggest threats of racism to protect themselves and in-group members [52]. In contrast, Whites are more motivated to disavow stereotypes that cast Whites as racists, and use a higher threshold for racist behaviors, often reserving them only to behaviors and attitudes that are blatantly racist $[45,53,54]$. To further illustrate, in experimental studies, Blacks and Whites developed different views of whether the same behavioral cues indicated racism [53-55]. While they tended to agree that explicit and blatant behaviors, such as racial violence, constituted racism, they disagreed about 
the nature of subtle or implicit racial bias that are expressed as micro-aggressions, or hostility. Minority study participants were more likely than White participants to be vigilant at identifying early warning signs and categorizing subtle, ambiguous behaviors as racism, whereas Whites had higher thresholds for these ambiguous cues and had less practice at recognizing them [55].

Studies have also shown that contextual factors, such as levels of historical knowledge of racism, previous past experiences of racism, and diversity policies, shape individuals' perceptions of racism [56-59]. For example, Blacks tend to compare racial progress to ideal standards of equality, while Whites tend to compare racial progress to the past, considering how much things have improved. Whites may also use salient examples of successful Blacks to signal racial progress and to counter beliefs that racism remains a legitimate reason or minorities' social disadvantage $[51,56,60,61]$

Divergent views of what signals racial threat to a group's racial identity can have consequences for policies aimed at reducing inequalities and for day-to-day interactions, including patient-provider communication. This study seeks to better understand situational cues in health encounters that may influence Black patients' perceptions of racial threat with the goal to improve their care experiences and ultimately, healthcare outcomes.

\section{Methods}

The data presented in this study are part of an exploratory, secondary analysis of a larger multi-methods study of patient-provider communication in mental health services (blinded citation). The primary study explores factors that influence minority veterans' engagement in VA mental health services and communication with mental health providers. The findings upon which this manuscript is based are from participants' discussions about the role of race in 
healthcare. All procedures were approved by the local Institutional Review Board. Informed consent and HIPAA authorization were obtained from study participants before enrollment.

\subsection{Sample and recruitment procedures}

The study was conducted at a VA Medical Center from April 2014 to May 2015.

Participants were Black veterans receiving outpatient mental health services. They were recruited using leaflets, letters, and snowball sampling - asking study participants to refer others to the project $[62,63]$. Data collection consisted of face-to-face interviews, collection of demographic data and clinical characteristics (e.g., diagnoses). Participants' race and ethnicity were obtained from medical records and corroborated by self-report.

\subsection{Interview guide}

We engaged participants in exploratory and non-directive discussions about factors that affect patient-provider communication for minority veterans, including whether race or racism played a role in healthcare interactions. Examples of questions included: 1) Does race affect patient-provider communication and that relationship? 2) How does your provider's race/ethnicity affect your relationship with him/her? While we asked participants whether they thought race plays a role in healthcare interactions, we purposefully did not provide a definition of race and racial bias so that participants could talk freely and guide the conversation in whatever direction they wanted. We matched the participants' and the interviewers' racial backgrounds to the extent possible to facilitate open discussions about their healthcare experiences and their views on race. The lead author who is Black conducted most of the interviews. Four research assistants conducted the remaining interviews; two were Black and two were White. Interviews lasted on average about an hour. 


\subsection{Analytic Approach}

Descriptive statistics were used to summarize demographic variables. We conducted data analysis using the constant comparative method $[64,65]$, a systematic qualitative methodology involving the discovery of theoretical insights through the joint coding of data and analysis. Because this study is a qualitative, exploratory secondary analysis, we conducted the data analysis process using an inductive approach, identifying codes and themes that emerged from the data. However, once the themes were developed and organized, the final data analysis involved using social identity theory to assist with data interpretation.

\subsection{Data Analysis Process}

Our data analysis process involved four phases. First, the lead author and a research assistant developed a coding book by reading sets of transcripts to identify key themes. To ensure coding consistency, both coders independently coded a random set of transcripts and compared their coding for consistency and clarification. We held regular coding meetings to refine our coding scheme and resolve inconsistencies through consensus. Once coding was stabilized, we used Atlas.ti, [66] [67] [68] [66], a qualitative data analysis software to code all transcripts. Second, we focused on specific codes to identify key salient themes and connections between different aspects of the data. Third, we contrasted major themes and related them to broader content areas discussed in the data. Lastly, we drew from social identity theory to assist with data interpretation.

\section{Results:}

\subsection{Participants' characteristics:}


We conducted semi-structured, qualitative interviews with 85 Black/African-American veterans. Demographics are summarized in Table 1. Most participants were male (76.7\%), unemployed $(57.0 \%)$, had an average age of $49.72(\mathrm{SD}=12.87)$, and had at least some college education $(69.8 \%)$.

\section{Insert Table near here}

Most of the participants reported positive patient-provider relationships or noted that race does not play a role in their care. However, given that the focus of the paper is on identity threatening cues and how they impact healthcare experiences and engagement, we limit discussion of our findings to these themes. We maintain that understanding of how perceptions of identity threatening cues could inform patient-provider communication and relationship to benefit all patients, especially those that experience perceived or real threat of racial bias.

Of the 85 participants, $22(26 \%)$ explicitly stated that race plays a role in healthcare. However, we included all 85 participants in our analysis because many participants who did not support this view discussed other relevant social factors such as culture and social background that influence minority veterans' healthcare experiences. For example, one participant who stated that race does not play a role in healthcare also claimed that he did not think a White provider could understand anything about "Black people and our dynamics." Given the nature of this exploratory qualitative data, all discussions related to race, social contexts, and identity, even from participants who did not endorse the view that race plays a role in healthcare were analyzed to inform our discussion.

Overall, two major themes emerged from the data that describe identity threatening cues in veterans' healthcare encounters: 1) Perceptions of how diversity is represented in healthcare 
settings; 2) Situational cues that signal identity threat by evoking feelings of being feared, judged, and disrespected in healthcare interactions.

\subsection{Perceptions of how diversity is represented in healthcare settings}

Participants identified lack of racial diversity representation in healthcare setting as an identity-threatening cue that informs their perceptions of their providers and healthcare organization. They explained that structural characteristics such as the physical space of an institution project how welcoming an institution might be to minority patients, and that staff diversity, especially in position of power, reflects the facility's values and culture related to racial equity. For example, participants often expressed pleasant surprise when they met our Black study staff and one shared the following during an interview with the first author:

I've just not experienced the diversity that they say there is here... I was not expecting a Haitian woman to be interviewing me. I would have bet money. . I'm glad. I may not have even been able to give some of the honest answers that I've been giving you, if it has been someone else. (51 years- old male)

The next excerpt further illustrates participants' evaluations of diversity representations and their interpretations of these cues as contributors to an identity-safe or threatening environment.

If you look at the administrative organizational chart when you walk into the building, you'll see the top guy up here, he's a White guy and his assistant is a Black lady... The next assistant down is a Hispanic, it plays an important part. . It was put up there to let people know who's running this place. The idea of a Black woman being the assistant administrator of this hospital makes a Black person feel pretty good.

He then contrasted this positive perception with artwork displayed in another part of the 
building:

The $[\mathrm{ART}]$ project, if you go where the atrium is, you see all these posters up on the wall. You don't see one brother, and you don't see one Mexican. . And you got all these White boys on this wall as though no Black person from [STATE in US] ever fought in combat. . . I don't think anybody's even noticed that. I don't think anybody is trying to be racist. But can you imagine how I feel? . . . There must be over 100 pictures down there. See, this is America. Your question was does it [race] play a role? Yeah, it plays a role. . . Veterans they look for things. You go to the wall and start looking at all these pictures. ...You say I wonder if any African-Americans are up here ... because you understand what has gone on before. (72 years-old male).

In this excerpt, the participant acknowledged that the omission of African-American heroes in the display may have been unintentional, yet it is nonetheless impactful.

\subsection{Situational cues that signal identity threat by evoking feelings of being feared, judged; and} disrespected in healthcare interactions.

The second theme that emerged from participants' discussions centered on cues that evoked feelings of being judged, feared, or stereotyped in healthcare encounters because of their racial identity. Participants described clinic visits where providers' words or actions expressed fear of Black veterans. For example, several participants described providers being distant, not wanting to touch them or take time to listen and address their concerns. Some participants also shared that because of their physical appearance, they felt stereotyped as "angry, big Black men." They explained that some providers viewed them as a physical threat and react fearfully. It's just something about African-American male that they perceive being a threat to them... They just wanna get you in that room and out as quick as they can. . They don't 
wanna spend time and really take care of you right. Sometimes you feel like they come in, they act like they scared to even talk to ya, and you get that feeling and then and if you got that feeling, they're kinda scared of you, you don't want them working on ya, do you? (56 years-old male)

Other participants discussed identity threatening cues that made them feel "looked down upon," "disrespected," and treated as an unequal partner in clinical interactions. Specifically, they described providers' perceived lack of interest in them as individuals, dismissal of their complaints, and use of condescending language. One participant explained:

I think sometimes that it [race] can play a part by the way a doctor talks to you or treats you with a lack of respect. .. when I would say something that was important to me, he would end up kind of turning it to a joke. He didn't seem like he was concerned about anything that I told him. There is still some racism in the medical field because he [provider] talked down to me and showed me no respect as a man ... It is awful. I would leave the VA thinking that I didn't get anything done. He just wasn't interested in how I felt. (66 years-old male)

In another example, a female veteran discussed her experiences of being stereotyped as a poor, uneducated Black woman.

They see me, an African-American female. . The first personification of us is ... that I have two children out of wedlock, I was an addict, I was incarcerated ... [they] think that I come from an impoverished background, [that] I have no education ... [They] talked to me as if I was a third grader ... just by the way they talk to me, it was really insulting. (47 years- old female) 
Participants also identified microaggressions in clinical encounters as identity threatening cues that could negatively affect patients' engagement behaviors and healthcare communication, as the next two excerpts show.

He [provider] needed to get me a copy of my meds. When he left the room, he told me, “Now don't touch my computer." ... I was thinking that he should know me well enough now to know that I'm not the kind of person that will want to steal from you or that will want to try to mess with his computer in any way. . . it reminded me that I was Black ... I don't let them really shock me because it's already something that I know I should expect. . . my ability to freely tell him some things for a short period of time may have been lowered. (68 years-old male)

The nurse said to me...: "What is the deal with Black men here [city]. There [are] not any fathers in the house..." I didn't let her know that it had offended me... I didn't act out because at that time, it would have been a negative way. I was mentally, physically in pain ... I already feel like that they expect us to act out, in a negative way, in a violent way. So, I want to kill that perception [of] African-American males, and not feed into it. (45 years-old male)

Both veterans in these examples interpreted providers' comments as identity threatening cues and situated them within larger historical contexts. Participants, like those in these excerpts, connected their negative healthcare experiences to broader experiences of being Black. Indeed, participants explained that providers may hold racial prejudices that manifest overtly or in subtle forms in interactions with minority veterans. A female veteran summarized this argument as follows: "Doctors are human beings. I think most physicians take the oath and mean to be colorblind. .... But, some people's personalities and some of the misconceptions that have been 
projected on Blacks make it difficult." Notably, for this participant, the notion of racial color blindness - the disregard of patients' racial characteristics in healthcare interactions - surfaces as an effective approach to address racial healthcare inequalities.

Recognizing that healthcare interactions and patient-provider communication occur within larger social contexts, some participants entered healthcare relationships with apprehension and vigilance, screening for identity-safe and threatening cues. One participant explained, "When I started coming here [VA], when I met with all my providers, I tried to read them to try to see if they are treating me based on my race." Another participant added:

Whenever I'm dealing with a healthcare provider when it comes to the VA, that's the first thing I think of: How they are gonna depict me? What are they gonna think about me? I usually try to pick it up on the first day of the conversations... If their first questions are: where are you from? what about your father? That's telling me they wanna know -stuff like have I been to jail? Might as well ask that. . that always seemed to have been the first questions. It's like stereotyping me already. And that's just the way I felt. . I've always been getting negative feedback or energy from them. I've always been judgmental towards them because of the way I was treated there. (32 years- old male)

As shown in these examples, participants used situational cues to shape perceptions of providers and treatment.

\section{Discussion and Conclusion}

\subsection{Discussion}

Our findings show that for some Black veterans, identity-safe and identity-threatening cues impact patient engagement and patient-provider communication. Non-verbal cues, such as workforce diversity and socially inclusive art displays are powerful signs that indicate to 
minority patients whether they will be welcome. While these signs may appear well-intentioned and innocuous to many, they can hold markedly different meanings for minority patients. Moreover, visual arts have been shown to enhance clinical settings and support healing experiences $[67,68]$. Use of socially inclusive art could provide additional benefits by creating affirmations for and making visible patients that have been traditionally marginalized in healthcare settings. These might be relatively easier actions for healthcare institutions to implement to create inclusive environment for minority populations.

Consistent with social identity theory, this finding further illustrates that minority groups are attuned to cues that signal social identity contingencies, including organizations' workforce diversity $[45,58,69]$. Many have argued that healthcare workforce diversity is important for the provision of culturally competent care, expansion of healthcare access for the underserved, and enrichment of the pool of policymakers to meet the needs of a diverse patient population [70, 71]. Yet, a recent study indicates that VA providers do not believe that workforce diversity is important for fostering health equity in their organization [72]. This study provides additional support for developing workforce diversity in the VA healthcare system to help create an identity-safe environment.

In this study, we illustrated that patients not only reacted to perceived racial threats in healthcare encounters but also pre-emptively searched for early warning signs to inform their healthcare behaviors and relationships. Studies have shown that perceived experiences of discrimination and even health care stereotype threats lead to negative physical and mental health outcomes [73-75]. Based on our findings, future research could examine the impact of pre-screening healthcare providers for identity-safe cues. For patients who already experience psychological distress, this additional cognitive task and emotional labor may keep them from 
effectively processing healthcare information and be fully engaged in healthcare interactions. It may also add to additional stress.

Participants' discussions also show how routine clinical interactions, such as asking a patient about his father, could be interpreted as an identity-threatening cue. However, as they explained, the contexts of the clinical interactions, as well as their past experiences of discrimination and history of racism against Blacks were critical in shaping their perceptions of these cues as threatening. These findings support the social identity theory that contextual factors, such as stereotypes about absent Black fathers, created perceptions of routine, situational cues and fear of being judged based on stereotypes that have characterized Black people.

\subsection{Conclusion}

This study represents a first step in exploring what factors minority veterans find identitythreating in VA mental healthcare and how they may affect their engagement in care and patientprovider communication. Theoretically significant, our study adds to a growing research on healthcare stereotype threats [75-77]. It helps sets the stage for future studies to examine how multiple identities intersect to affect experiences of racial bias, and to explore different strategies that patients employ to prevent, cope with, or reduce the impact of perceived bias in healthcare encounters.

This study has some limitations. It was conducted at one VA facility. It is not representative of all veterans and minority veterans. Therefore, our findings should be interpreted with caution. Also, the data for this study were collected in 2014 and 2015, during the Obama administration, which some researchers and politicians have characterized as "post-racial." [78, 79]. The recent shift in social and political climates may affect minority veterans' views and experiences of race in healthcare encounters. In that regard, this study may provide a useful point 
of reference to compare changes in patients' perspectives based on larger sociohistorical events. Our findings also warrant future research to further investigate how sociopolitical contexts impact patients' healthcare experiences, especially in this current era of increased racial tension and racial violence in the US.

\subsection{Implications for practice}

Findings from this study have several implications for patient engagement. Identitythreatening cues may serve as barriers to engage minority patients in healthcare services. The challenge therefore remains how providers can effectively respond to the unique needs of diverse minority populations. This is an enormous task as minority populations are "hyper-diverse," representing different races, ethnicities, cultures and values, and divergent views of racial bias [80]. Training providers in cultural competence is not enough to address bias in care [81, 82]. For providers, recognizing the presence and impact of identity-threatening cues for minority groups may be the first step in creating a more inclusive healthcare environment. Using a personcentered approach to care that involves assessing what matters the most to patients and incorporating shared decision-making processes may be particularly relevant and useful for minority patients, especially when they do not share the same sociocultural backgrounds with their providers $[28,80]$.

While it may be difficult to prevent manifestation of implicit biases and divergent views of cues indicating racial bias, strong interpersonal relationships and open communication between patients and providers may help weather negative healthcare interactions [26, 83]. Providers may start by asking patients about their past negative healthcare experiences and develop understanding of sociocultural factors that could influence patients' healthcare experiences and relationships. In addition to interpersonal factors, organizational structures are 
needed to support providers in providing equitable care, such as infrastructure that facilitate training and resources needed to engage patients in shared decision-making and to address social determinants of health. Providers who are burnt out are more likely to exhibit behaviors that are perceived as racial bias $[5,9]$. Therefore, reducing burnout and helping providers to be mindful and sensitive to patients' preferences and unique needs may help create respectful, identity safe healthcare environments. 


\section{References}

1. Hall, W.J., et al., Implicit Racial/Ethnic Bias Among Health Care Professionals and Its Influence on Health Care Outcomes: A Systematic Review. Am J Public Health, 2015. 105(12): p. e60-76.

2. FitzGerald, C. and S. Hurst, Implicit bias in healthcare professionals: a systematic review. BMC Med Ethics, 2017. 18(1): p. 19.

3. Sabin, J.A., F.P. Rivara, and A.G. Greenwald, Physician implicit attitudes and stereotypes about race and quality of medical care. Med Care, 2008. 46(7): p. 678-85.

4. Bailey, Z.D., et al., Structural racism and health inequities in the USA: evidence and interventions. Lancet, 2017. 389(10077): p. 1453-1463.

5. Dyrbye, L., et al., Association of Racial Bias With Burnout Among Resident Physicians. JAMA Netw Open, 2019. 2(7): p. e197457.

6. Cooper, L.A., et al., The associations of clinicians' implicit attitudes about race with medical visit communication and patient ratings of interpersonal care. Am J Public Health, 2012. 102(5): p. 979-87.

7. Sabin, J.A., et al., Clinicians' Implicit and Explicit Attitudes about Weight and Race and Treatment Approaches to Overweight for American Indian Children. Child Obes, 2015. 11(4): p. 456-65.

8. Green, A.R., et al., Implicit bias among physicians and its prediction of thrombolysis decisions for black and white patients. J Gen Intern Med, 2007. 22(9): p. 1231-8.

9. Burgess, D.J., Are providers more likely to contribute to healthcare disparities under high levels of cognitive load? How features of the healthcare setting may lead to biases in medical decision making. Med Decis Making, 2010. 30(2): p. 246-57.

10. Burgess, D.J., et al., The effect of cognitive load and patient race on physicians' decisions to prescribe opioids for chronic low back pain: a randomized trial. Pain Med, 2014. 15(6): p. 965-74.

11. Powell, W., et al., Medical Mistrust, Racism, and Delays in Preventive Health Screening Among African-American Men. Behav Med, 2019. 45(2): p. 102-117.

12. Patel, N., et al., Unconscious Racial Bias May Affect Dentists' Clinical Decisions on Tooth Restorability: A Randomized Clinical Trial. JDR Clin Trans Res, 2019. 4(1): p. 19-28.

13. Van Houtven, C.H., et al., Perceived discrimination and reported delay of pharmacy prescriptions and medical tests. J Gen Intern Med, 2005. 20(7): p. 578-83.

14. Enard, K.R., L. Nevarez, and D.M. Ganelin, Association Between Perceived Discrimination and Emergency Department Use Among Safety-Net Patients in the Southwestern United States. South Med J, 2018. 111(1): p. 1-7.

15. Jacobs, E.A., et al., Perceived discrimination is associated with reduced breast and cervical cancer screening: the Study of Women's Health Across the Nation (SWAN). J Womens Health (Larchmt), 2014. 23(2): p. 138-45.

16. Burgess, D.J., et al., The association between perceived discrimination and underutilization of needed medical and mental health care in a multi-ethnic community sample. J Health Care Poor Underserved, 2008. 19(3): p. 894-911.

17. Trivedi, A.N. and J.Z. Ayanian, Perceived discrimination and use of preventive health services. J Gen Intern Med, 2006. 21(6): p. 553-8.

18. Casagrande, S.S., et al., Perceived discrimination and adherence to medical care in a racially integrated community. J Gen Intern Med, 2007. 22(3): p. 389-95.

19. Beach, M.C., J. Keruly, and R.D. Moore, Is the quality of the patient-provider relationship associated with better adherence and health outcomes for patients with HIV? J Gen Intern Med, 2006. 21(6): p. 661-5. 
20. Kelley, J.M., et al., The influence of the patient-clinician relationship on healthcare outcomes: $a$ systematic review and meta-analysis of randomized controlled trials. PLoS One, 2014. 9(4): p. e94207.

21. Asare, M., et al., The Patient-Provider Relationship: Predictors of black/African American Cancer Patients' Perceived Quality of Care and Health Outcomes. Health Commun, 2019: p. 1-6.

22. Blair, I.V., et al., Clinicians' implicit ethnic/racial bias and perceptions of care among Black and Latino patients. Ann Fam Med, 2013. 11(1): p. 43-52.

23. Babulal, G.M., et al., Perspectives on ethnic and racial disparities in Alzheimer's disease and related dementias: Update and areas of immediate need. Alzheimers Dement, 2019. 15(2): p. 292-312.

24. Gonzalez, C.M., et al., Patient perspectives on racial and ethnic implicit bias in clinical encounters: Implications for curriculum development. Patient Educ Couns, 2018. 101(9): p. 16691675.

25. Eliacin, J., et al., Factors influencing patients' preferences and perceived involvement in shared decision-making in mental health care. J Ment Health, 2015. 24(1): p. 24-8.

26. Eliacin, J., et al., Patients' understanding of shared decision making in a mental health setting. Qual Health Res, 2015. 25(5): p. 668-78.

27. Matthias, M.S., et al., Consumer and relationship factors associated with shared decision making in mental health consultations. Psychiatr Serv, 2014. 65(12): p. 1488-91.

28. Eliacin, J., et al., The Relationship Between Race, Patient Activation, and Working Alliance: Implications for Patient Engagement in Mental Health Care. Adm Policy Ment Health, 2018. 45(1): p. 186-192.

29. White, R.O., et al., Health communication, self-care, and treatment satisfaction among lowincome diabetes patients in a public health setting. Patient Educ Couns, 2015. 98(2): p. 144-9.

30. Trzeciak, S., et al., Association Between Medicare Summary Star Ratings for Patient Experience and Clinical Outcomes in US Hospitals. J Patient Exp, 2016. 3(1): p. 6-9.

31. Johnson, R.L., et al., Racial and ethnic differences in patient perceptions of bias and cultural competence in health care. J Gen Intern Med, 2004. 19(2): p. 101-10.

32. Hausmann, L.R., et al., Perceived racial discrimination in health care and its association with patients' healthcare experiences: does the measure matter? Ethn Dis, 2010. 20(1): p. 40-7.

33. Vina, E.R., et al., Perceptions of racism in healthcare among patients with systemic lupus erythematosus: a cross-sectional study. Lupus Sci Med, 2015. 2(1): p. e000110.

34. Abramson, C.M., M. Hashemi, and M. Sanchez-Jankowski, Perceived discrimination in U.S. healthcare: Charting the effects of key social characteristics within and across racial groups. Prev Med Rep, 2015. 2: p. 615-21.

35. Benjamins, M.R. and M. Middleton, Perceived discrimination in medical settings and perceived quality of care: A population-based study in Chicago. PLoS One, 2019. 14(4): p. e0215976.

36. Hudelson, P., V. Kolly, and T. Perneger, Patients' perceptions of discrimination during hospitalization. Health Expect, 2010. 13(1): p. 24-32.

37. Weech-Maldonado, R., et al., The relationship between perceived discrimination and patient experiences with health care. Med Care, 2012. 50(9 Suppl 2): p. S62-8.

38. Quach, T., et al., Experiences and perceptions of medical discrimination among a multiethnic sample of breast cancer patients in the Greater San Francisco Bay Area, California. Am J Public Health, 2012. 102(5): p. 1027-34.

39. Tajeu, G.S., et al., "We'll Get to You When We Get to You": Exploring Potential Contributions of Health Care Staff Behaviors to Patient Perceptions of Discrimination and Satisfaction. Am J Public Health, 2015. 105(10): p. 2076-82. 
40. Purdie-Vaughns, V., et al., Social identity contingencies: how diversity cues signal threat or safety for African Americans in mainstream institutions. J Pers Soc Psychol, 2008. 94(4): p. 615-30.

41. Hatzfeld, J.J., et al., African-American perceptions of health disparities: a qualitative analysis. J Natl Black Nurses Assoc, 2008. 19(1): p. 34-41.

42. Gaston-Johansson, F., et al., Patient perspectives on disparities in healthcare from AfricanAmerican, Asian, Hispanic, and Native American samples including a secondary analysis of the Institute of Medicine focus group data. J Natl Black Nurses Assoc, 2007. 18(2): p. 43-52.

43. Steele, C.M., S. Spencer, and J. Aronson, Contending with group image: The psychology of stereotype and social identity threat. , in Advances in experimental social psychology, M.P.E. Zanna, Editor. 2002, Academic Press. : San Diego, CA: . p. 379-440.

44. Tajfel, H. and J.C. Turner, The social identity theory of inter-group behavior. In in Psychology of intergroup relations, S. Worchel, Austin, L.W. (Eds.),, Editor. 1986, Nelson-Hall. : Chicago:. p. 724

45. Goff, P.A., C.M. Steele, and P.G. Davies, The space between us: Stereotype threat and distance in interracial

contexts. Journal of Personality and Social Psychology,, 2008. 94(1): p. 91-107.

46. Burgess, D.J., et al., Stereotype threat and health disparities: what medical educators and future physicians need to know. J Gen Intern Med, 2010. 25 Suppl 2: p. S169-77.

47. Hausmann, L.R., et al., Impact of perceived discrimination in healthcare on patient-provider communication. Med Care, 2011. 49(7): p. 626-33.

48. Greer, T.M., Perceived racial discrimination in clinical encounters among African American hypertensive patients. J Health Care Poor Underserved, 2010. 21(1): p. 251-63.

49. Mende-Siedlecki, P., et al., Perceptual contributions to racial bias in pain recognition. J Exp Psychol Gen, 2019. 148(5): p. 863-889.

50. Williams, D.R. and S.A. Mohammed, Discrimination and racial disparities in health: evidence and needed research. J Behav Med, 2009. 32(1): p. 20-47.

51. Carter, E.R. and M.C. Murphy, Group-based Differences in Perceptions of Racism: What

Counts, to Whom, and Why? Social and Personality Psychology Compass 2015. 9(6): p. 269-280.

52. Shelton, J.N., J.A. Richeson, and J. Salvatore, Expecting to be the target of prejudice: Implications for interethnic

interactions. Personality and Social Psychology Bulletin, 2005. 21(9): p. 1189-1202.

53. Salvatore, J. and J.N. Shelton, Cognitive costs of exposure to racial prejudice. . Psychological Science,, 2007. 18(9): p. 810-815.

54. Schmitt, M.T., \& Branscombe, N. R., The meaning and consequences of perceived discrimination in disadvantaged

and privileged social groups, in in W. Stroebe \& M. Hewstone (Eds.) European review of social psychology 2002, John Wiley \& Sons.

Shelton, J. N., Richeson, J. A., \& Salvatore, J. (2005). E: Hoboken, NJ:. p. 167-199.

55. Sommers, S.R. and M.I. Norton, Lay theories about white racists: What constitutes racism (and what doesn't). Group

Processes and Intergroup Relations, 2006. 9(1): p. 117-138.

56. Eibach, R.P. and V. Purdie-Vaughns, How to keep on keeping on: Framing civil rights accomplishments to bolster

support for egalitarian policies. Journal of Experimental Social Psychology, 2011. 47(1): p. 274-277. 
57. Lewis, V.J., et al., Black Adolescent Females' Perceptions

of Racial Discrimination When Accessing

Reproductive and General Health Care. Sage Open, 2016. 6(3).

58. Kaiser, C.R., et al., Presumed fair: Ironic effects of

organizational diversity structures. Journal of Personality and Social Psychology,, 2013. 104(3): p. 504519.

59. Plaut, V., et al., What about me?" Perceptions of exclusion and Whites' reactions to multiculturalism. Journal of Personality and Social Psychology, , 2011. 101(2): p. 337-353.

60. Lybarger, J.E., \& Monteith, M. J. , The effect of Obama saliency on individual-level racial bias: Silver bullet or

smokescreen? Journal of Experimental Social Psychology, 2011. 47: p. 647-652.

61. Brodish, A.B., P.C. Brazy, and P.G. Devine, More Eyes on the Prize: Variability in White Americans' Perceptions of Progress Toward Racial Equality. Personality and Social Psychology Bulletin, 2008. 34(4): p. 513-527.

62. Kadushin, C., Power, influence and social circles: A new methodology for studying opinion makers. . American Sociological Review, , 1968. 33(5): p. 685-699.

63. Bernard, H.R., Research Methods in Anthropology: Qualitative and Quantitative Approaches. 2011: AltaMira Pess.

64. Glaser, B.G. and A.L. Strauss, The Discovery of Grounded Theory: Strategies for Qualitative Research. 1967, Chicago: Aldine Publishing Company.

65. Lincoln Y and G. E., Naturalistic Inquiry;. 1985, Beverly Hills, CA: Sage Publications Inc. pp. 334341. .

66. "ATLAS.ti: The Qualitative Data Analysis \& Research Software". ATLAS.ti vs. 7.

67. Nielsen, S.L., et al., How do patients actually experience and use art in hospitals? The significance of interaction: a user-oriented experimental case study. Int J Qual Stud Health Well-being, 2017. 12(1): p. 1267343.

68. Stuckey, H.L. and J. Nobel, The connection between art, healing, and public health: a review of current literature. Am J Public Health, 2010. 100(2): p. 254-63.

69. M.Steele, C., S. J.Spencer, and JoshuaAronson, Contending with group image: The psychology of stereotype and social identity threat. Advances in Experimental Social Psychology, 2002. 34: p. 379-440.

70. Snyder, C.R., B.K. Frogner, and S.M. Skillman, Facilitating Racial and Ethnic Diversity in the Health Workforce. J Allied Health, 2018. 47(1): p. 58-65.

71. Shahi, A., F. Karachiwalla, and N. Grewal, Walking the Walk: The Case for Internal Equity, Diversity, and Inclusion Work Within the Canadian Public Health Sector. Health Equity, 2019. 3(1): p. 183-185.

72. Eliacin, J., et al., Veterans Affairs Providers' Beliefs About the Contributors to and Responsibility for Reducing Racial and Ethnic Health Care Disparities. Health Equity, 2019. 3(1): p. 436-448.

73. Yang, T.C. and D. Chen, A multi-group path analysis of the relationship between perceived racial discrimination and self-rated stress: how does it vary across racial/ethnic groups? Ethn Health, 2018. 23(3): p. 249-275.

74. Pascoe, E.A. and L. Smart Richman, Perceived discrimination and health: a meta-analytic review. Psychol Bull, 2009. 135(4): p. 531-54.

75. Abdou, C.M., et al., Healthcare Stereotype Threat in Older Adults in the Health and Retirement Study. Am J Prev Med, 2016. 50(2): p. 191-8. 
76. Abdou, C.M. and A.W. Fingerhut, Stereotype threat among black and white women in health care settings. Cultur Divers Ethnic Minor Psychol, 2014. 20(3): p. 316-23.

77. Jones, P.R., et al., Health-Related Stereotype Threat Predicts Health Services Delays Among Blacks. Race Soc Probl, 2013. 5(2): p. 121-136.

78. Haney-López, I.F., Is the Post in Post-Racial the Blind in Colorblind. Cardozo L. Rev, 2010. 32: p. 807.

79. Love, B.L. and B. Tosolt, Reality or Rhetoric? Barack Obama and Post-Racial America. Race, Gender \& Class, 2010. 17(3/4): p. 19-37.

80. Alegría, M., Alvarez, K., Ishikawa, R. Z., DiMarzio, K., \& McPeck, S. , Removing Obstacles To Eliminate Racial And Ethnic Disparities In Behavioral Health Care. . Health Affairs 2016. 35(6): p. 991-999.

81. Lie, D.A., et al., Does cultural competency training of health professionals improve patient outcomes? A systematic review and proposed algorithm for future research. J Gen Intern Med, 2011. 26(3): p. 317-25.

82. Jongen, C., J. McCalman, and R. Bainbridge, Health workforce cultural competency interventions: a systematic scoping review. BMC Health Serv Res, 2018. 18(1): p. 232.

83. Matthias, M.S., T.L. Talib, and M.A. Huffman, Managing Chronic Pain in an Opioid Crisis: What Is the Role of Shared Decision-Making? Health Commun, 2019: p. 1-9. 